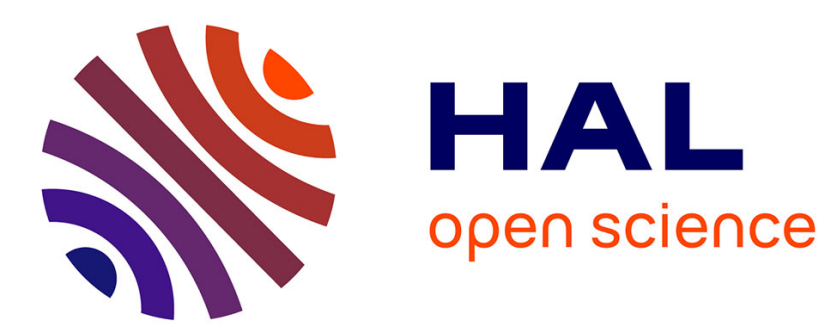

\title{
An electrochemical and surface analytical study of the formation of nanoporous oxides on niobium
} Bogdan Tzvetkov, Martin Bojinov, Assen Girginov, Nadine Pébère

\section{To cite this version:}

Bogdan Tzvetkov, Martin Bojinov, Assen Girginov, Nadine Pébère. An electrochemical and surface analytical study of the formation of nanoporous oxides on niobium. Electrochimica Acta, 2007, vol. 52, pp. 7724-7731. 10.1016/j.electacta.2006.12.034 . hal-00806031

\section{HAL Id: hal-00806031 \\ https://hal.science/hal-00806031}

Submitted on 29 Mar 2013

HAL is a multi-disciplinary open access archive for the deposit and dissemination of scientific research documents, whether they are published or not. The documents may come from teaching and research institutions in France or abroad, or from public or private research centers.
L'archive ouverte pluridisciplinaire HAL, est destinée au dépôt et à la diffusion de documents scientifiques de niveau recherche, publiés ou non, émanant des établissements d'enseignement et de recherche français ou étrangers, des laboratoires publics ou privés. 


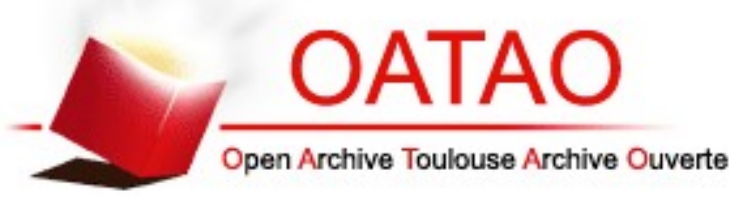

\section{Open Archive Toulouse Archive Ouverte (OATAO)}

OATAO is an open access repository that collects the work of Toulouse researchers and makes it freely available over the web where possible.

This is an author-deposited version published in: http://oatao.univ-toulouse.fr/ Eprints ID : 2421

To link to this article :

URL : http://dx.doi.org/10.1016/j.electacta.2006.12.034

To cite this version : Tzvetkov, Bogdan and Bojinov, Martin and Girginov, Assen and Pébère, Nadine ( 2007) An electrochemical and surface analytical study of the formation of nanoporous oxides on niobium. Electrochimica Acta, vol. 52 ( $\left.\mathrm{n}^{\circ} 27\right)$. pp. 7724-7731. ISSN 0013-4686

Any correspondence concerning this service should be sent to the repository administrator:staff-oatao@inp-toulouse.fr 


\title{
An electrochemical and surface analytical study of the formation of nanoporous oxides on niobium
}

\author{
Bogdan Tzvetkov $^{\mathrm{a}}$, Martin Bojinov ${ }^{\mathrm{a}, *, 1}$, Assen Girginov $^{\mathrm{a}}$, Nadine Pébère ${ }^{\mathrm{b}, 1}$ \\ a Department of Physical Chemistry, University of Chemical Technology and Metallurgy, \\ Kl. Ohridski Blvd. 8, 1756 Sofia, Bulgaria \\ b CIRIMAT/UMR CNRS 5085, ENSIACET, 31077 Toulouse, France
}

\begin{abstract}
In the present paper, the anodization of $\mathrm{Nb}$ in mixed sulphate + fluoride electrolytes resulting in the formation of a nanoporous oxide film has been studied. Chronoamperometry and electrochemical impedance spectroscopy have been employed to characterise in situ the kinetics of the oxidation process. In addition, the evolution of the layer structure and morphology has been followed by ex situ scanning electron microscopy. Particularly, local electrochemical impedance spectroscopy has been used to discern between the mesoscopic 2D and 3D distributions of time constants at the electrode surface. The similarity between local and global impedance spectra during anodic oxidation of Nb demonstrates the presence of an inherent 3D distribution of the high-frequency time constant, which is interpreted as in-depth variation of the steady state conductivity of the passive film. The experimental and calculational results are discussed in relation to the micro- and nanoscopic structure of the formed oxide.
\end{abstract}

Keywords: Niobium; Anodic oxidation; Porous oxide; Local electrochemical impedance spectroscopy; 2D and 3D distributions

\section{Introduction}

The anodization of niobium and other valve metals in suitable electrolytes has recently been found to be a particularly promising method of producing self-organised nanotube arrays on such materials [1-3] that would bear high application potential as gas sensors, catalytic matrices and catalysts, optical and electrochromic devices [3-7]. On the other hand, the interplay between oxide film formation and metal dissolution through the film, as necessary prerequisites for the porous overlayer growth, has been demonstrated already in the very first stages of passivation of $\mathrm{Nb}$ [8]. From the point of view of corrosion prevention in general, the disclosure of the mechanism of formation of porous layers on metals could lead to the minimisation of the extent of localised corrosion damage on technically important materials, such as aluminium and titanium based alloys. In that respect, owed to the spatial variation of the rates of different stages of the overall corrosion

\footnotetext{
* Corresponding author. Tel.: +3592 8163 430; fax: +3592 8682036 .

E-mail address: martin@uctm.edu (M. Bojinov).

1 ISE Member.
}

process, there is need to employ local techniques that are able to follow the process in situ and provide information on individual reaction step rates, such as the recently developed local electrochemical impedance spectroscopy $[9,10]$.

In that context, the objective of the present work is to investigate the nanoporous oxide formation on $\mathrm{Nb}$ by anodic oxidation in sulphate + fluoride electrolytes. Chronoamperometry and electrochemical impedance spectroscopy are employed to characterise the kinetics of the oxidation process. The evolution of the layer structure and morphology is followed by ex situ scanning electron microscopy (SEM). In an attempt to assess quantitatively the mechanism of film formation, the growth of the barrier sublayer is modelled in analogy to previous work on the anodization of $\mathrm{Nb}$ in $\mathrm{HF}$ containing solutions [11]. Local electrochemical impedance spectroscopy is applied to discern between the mesoscopic 2D and 3D distributions of time constants related to the heterogeneity of both the bulk oxide and the oxide/solution interface [10]. As a result, reliable estimates of the high-frequency capacitance and hence the thickness of the barrier layer could be obtained. The experimental and calculation results are discussed in relation to the micro- and nanoscopic structure of the porous oxide film. 


\section{Experimental}

The working electrode material was pure $\mathrm{Nb}(99.9 \%$, Goodfellow), manufactured in the form of a disc or sheet. The working electrodes were mechanically abraded with emery paper up to grade 4000, in the case of local impedance, followed by polishing with alumina paste. The electrolytes were prepared from reagent grade $\mathrm{Na}_{2} \mathrm{SO}_{4}$ and HF. Current versus time curves and conventional electrochemical impedance spectra were registered with a Solartron 1287/1250 system in the frequency range $65 \mathrm{kHz}-0.02 \mathrm{~Hz}$ typically at an ac amplitude of $10-20 \mathrm{mV}$ (rms). A conventional electrolytic cell featuring a Pt counter electrode and a saturated calomel reference electrode was employed. To register local impedance spectra at different points on the electrode surface, a Solartron 1287 system was employed in a five-electrode configuration $[9,10]$. In such a configuration, the local measured current depends on the conductivity of the electrolyte. Thus, anodization was carried out in $0.001 \mathrm{M} \mathrm{Na}_{2} \mathrm{SO}_{4}+0.2 \% \mathrm{HF}$ electrolyte instead of the more commonly employed $1 \mathrm{M} \mathrm{H}_{2} \mathrm{SO}_{4}+(0.2-1 \%) \mathrm{HF}$ mixtures [2] in order to improve the resolution of the method. The linearity of the impedance was verified by measuring spectra at different amplitudes between 2 and $10 \mathrm{mV}$, whereas the causality was determined by a Kramers-Kronig compatibility test. Data that did not pass the test (usually at the low-frequency end) were rejected. Fitting of the impedance spectra was performed using ZView software (Scribner). For the microscopic observations, FE-SEM technique (JEOL_JSM 6700F) was employed in order to achieve better lateral resolution.

\section{Results and discussion}

Fig. 1 shows FE-SEM micrographs of the surface of $\mathrm{Nb}$ oxidised for $1 \mathrm{~h}$ in $1 \mathrm{M} \mathrm{H}_{2} \mathrm{SO}_{4}$ (above) or $0.001 \mathrm{M} \mathrm{Na}_{2} \mathrm{SO}_{4}$ (below) containing $0.2 \% \mathrm{HF}$ at $5 \mathrm{~V}$. A two-scale microstructure is observed in a certain analogy to that reported previously by other authors $[2,3,12]$-irregular circular shapes of crystallized oxide with a lateral dimension of ca. $250 \mathrm{~nm}$ and nanopores with a mean diameter of $15-30 \mathrm{~nm}$. What is more important, the structures obtained in both electrolytes are very similar, which enables further investigations to be performed in the more dilute sulphate electrolyte.

Current versus time curves and impedance spectra were measured in the potential range from 3 to $10 \mathrm{~V}$ in order to characterise the kinetics of film formation and the conduction mechanism in the oxide. Fig. 2 shows the current versus time curves of $\mathrm{Nb}$ measured in $0.001 \mathrm{M} \mathrm{Na}_{2} \mathrm{SO}_{4}+0.2 \% \mathrm{HF}$ in the potential range $3-9 \mathrm{~V}$, in which the nanoporous structures are formed, as evidenced by FE-SEM. The current versus time curves are similar to those reported previously by other authors in $\mathrm{H}_{2} \mathrm{SO}_{4}$ and $\mathrm{H}_{3} \mathrm{PO}_{4}$ solutions containing $\mathrm{HF}[2,3]$ and depict the formation of the barrier layer (till the minimum of the curves) and the subsequent growth of the nanoporous overlayer (the current increase and stabilisation). A noteworthy fact is that the steady-state current density does not depend on potential (at least above $3 \mathrm{~V}$ ), which demonstrates that it is controlled by the rate of chemical dissolution of the barrier film and its
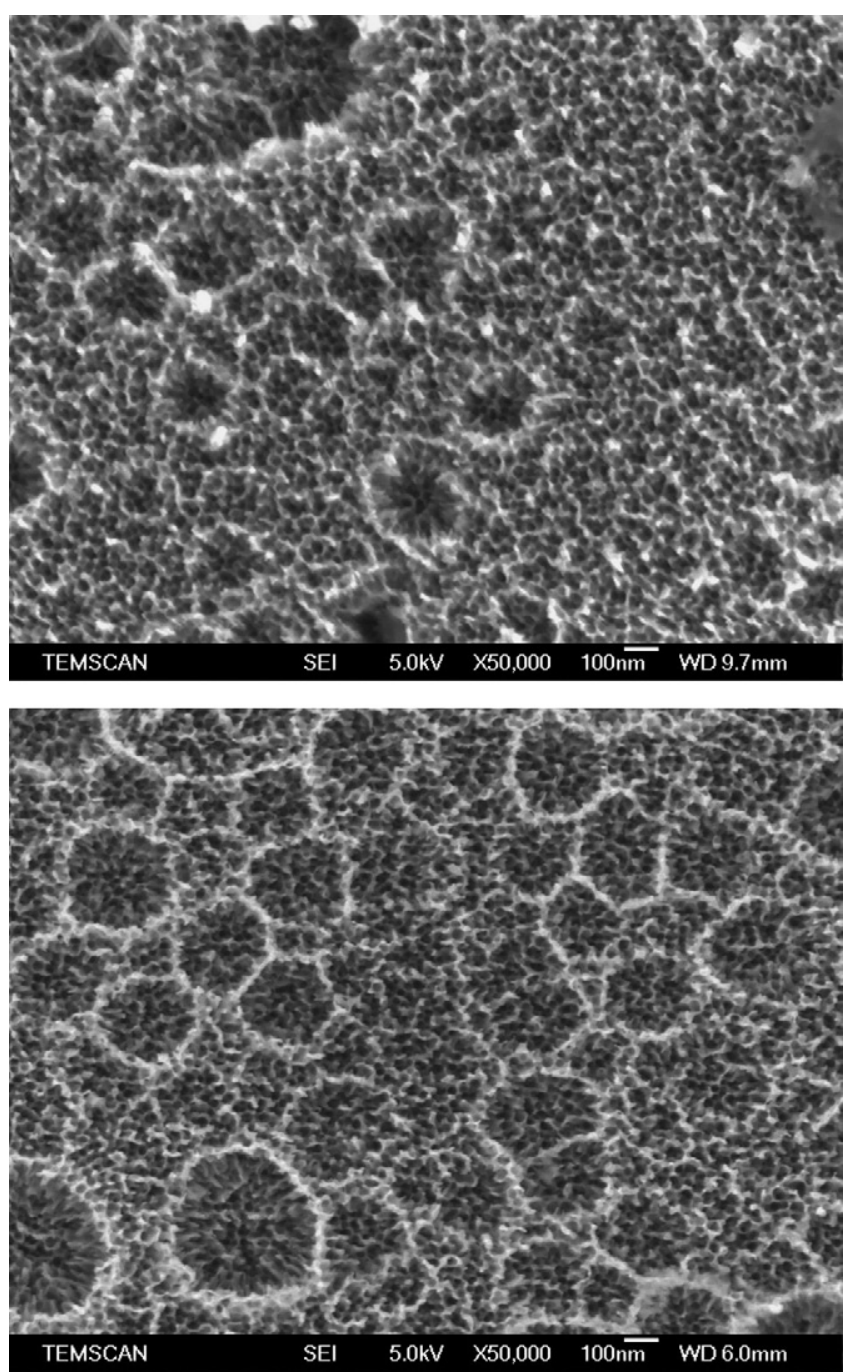

Fig. 1. FE-SEM observations of anodic films formed on $\mathrm{Nb}$ in $1 \mathrm{M}$ $\mathrm{H}_{2} \mathrm{SO}_{4}+0.2 \% \mathrm{HF}$ (above) and $0.001 \mathrm{M} \mathrm{Na}_{2} \mathrm{SO}_{4}+0.2 \% \mathrm{HF}$ (below) for $1 \mathrm{~h}$ at $5 \mathrm{~V}$.

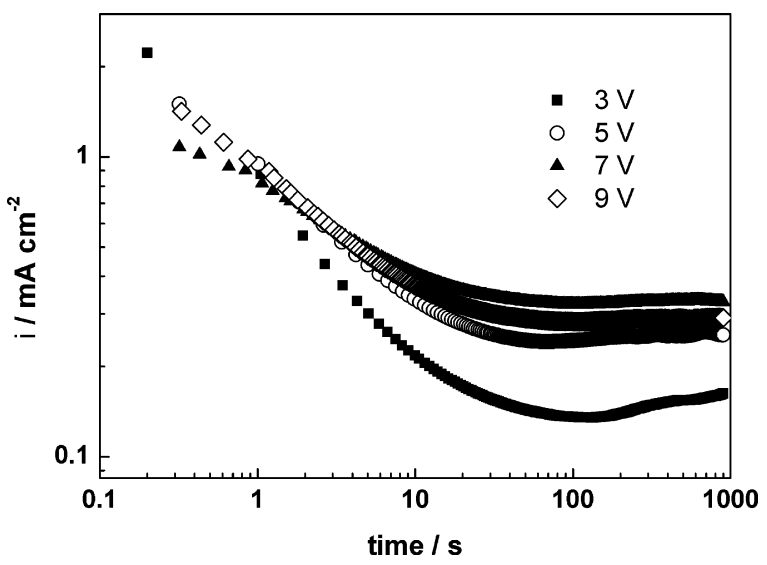

Fig. 2. Current density vs. time curves for $\mathrm{Nb}$ in $0.001 \mathrm{M} \mathrm{Na}_{2} \mathrm{SO}_{4}+0.2 \% \mathrm{HF}$ as depending on oxidation potential. Oxidation time $1 \mathrm{~h}$. 

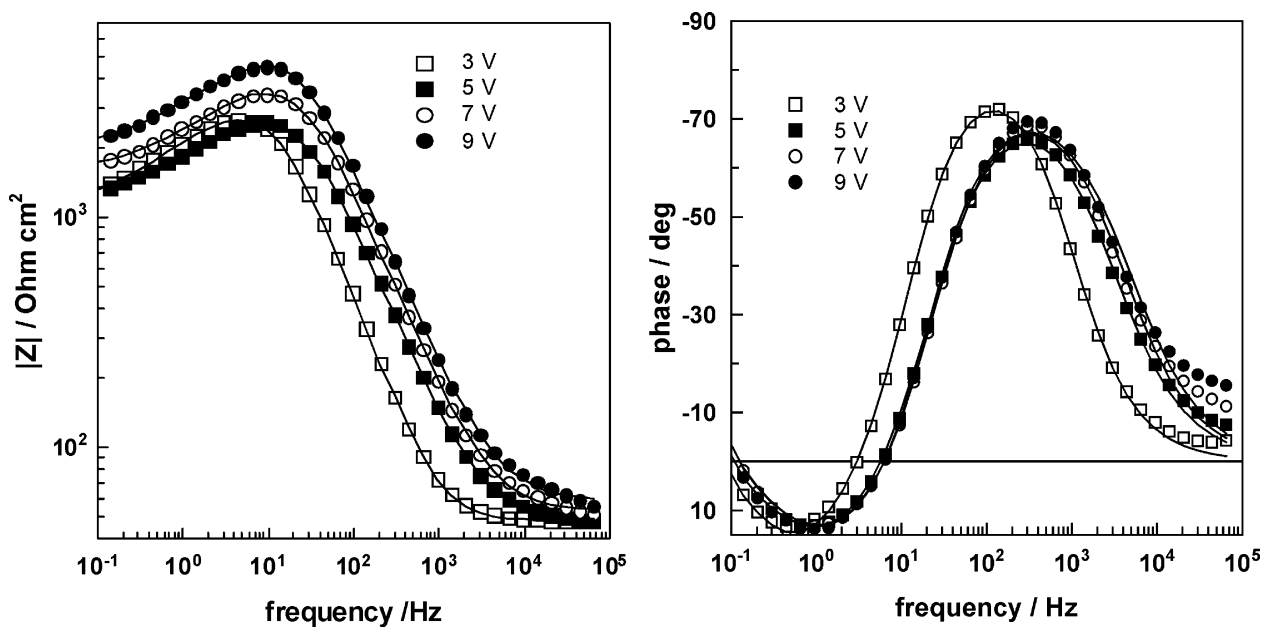

Fig. 3. Global impedance spectra for $\mathrm{Nb}$ in $0.001 \mathrm{M} \mathrm{Na}_{2} \mathrm{SO}_{4}+0.2 \% \mathrm{HF}$ as depending on oxidation potential. Oxidation time $1 \mathrm{~h}$.

transformation to a porous layer at the electrolyte interface $[2,3,11]$.

The corresponding global impedance spectra obtained after the steady-state current density has been reached are shown in Fig. 3. They are qualitatively similar to those previously measured in sulphate + fluoride solutions by Cattarin et al. [11]. The spectra exhibit two time constants-a high-frequency capacitive one, corresponding to the parallel combination of the barrier layer capacitance and the resistance of major point defect migration through it, and a low-frequency pseudo-inductive time constant arising from the acceleration of major point defect migration rate via interaction with oppositely charged point defects $[8,13]$. To a first approximation, these spectra have been modelled according to the surface-charge approach $[8,11,13]$, which is able to account both for the impedance magnitude and its frequency dependence. A major unresolved point, however, is the fact that both time constants are distributed, i.e. their description using classical capacitance and inductance does not result in a perfect fit to the data.

Concerning the high-frequency time constant, the so-called constant phase element (CPE) behaviour has been frequently invoked to explain the deviations from the ideal capacitive arc, and it has been attributed to both 2D (geometrical, energetical) or 3D distributions of either the dielectric constant or the conductivity [10] of the film. It has been recently demonstrated that local impedance spectroscopy can be used to discern between 2D and 3D distributions [10].

Local impedance spectra in the centre of the $\mathrm{Nb}$ electrode in otherwise similar conditions are shown in Fig. 4. These spectra are completely analogous to the global impedance spectra in what concerns the frequency dependence of the impedance, the deviations from pure capacitive and inductive features at high and low frequencies respectively being preserved. The same behaviour is further confirmed by the local impedance spectra registered at $5 \mathrm{~V}$ and different locations on the surface (Fig. 5). According to the analysis presented in Ref. [10] for passive Al, the global impedance is most probably a sum of radially distributed 2D local impedances, each one of which has an inherently 3D character. Indeed the impedance magnitude at low frequencies that can be associated with the migration resistance is higher at the periphery of the electrode than in the centre, and at the same time the deviations of both time constants from
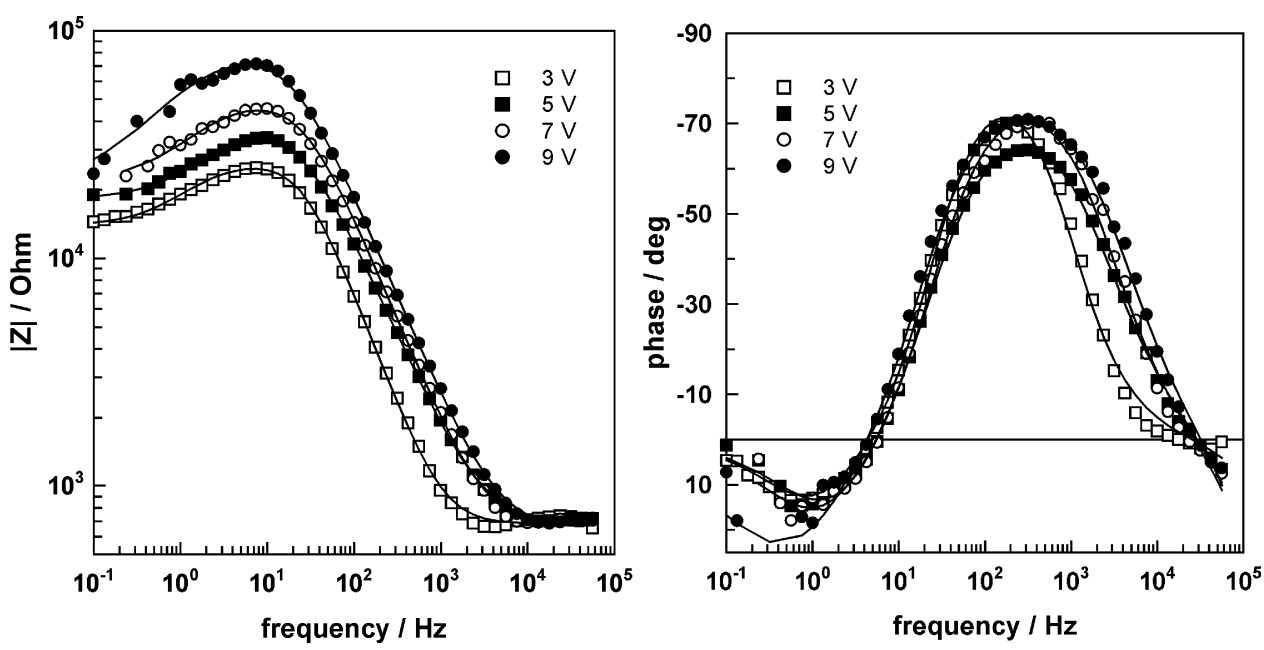

Fig. 4. Local impedance spectra at the centre of the electrode in conditions similar to those in Fig. 3. 

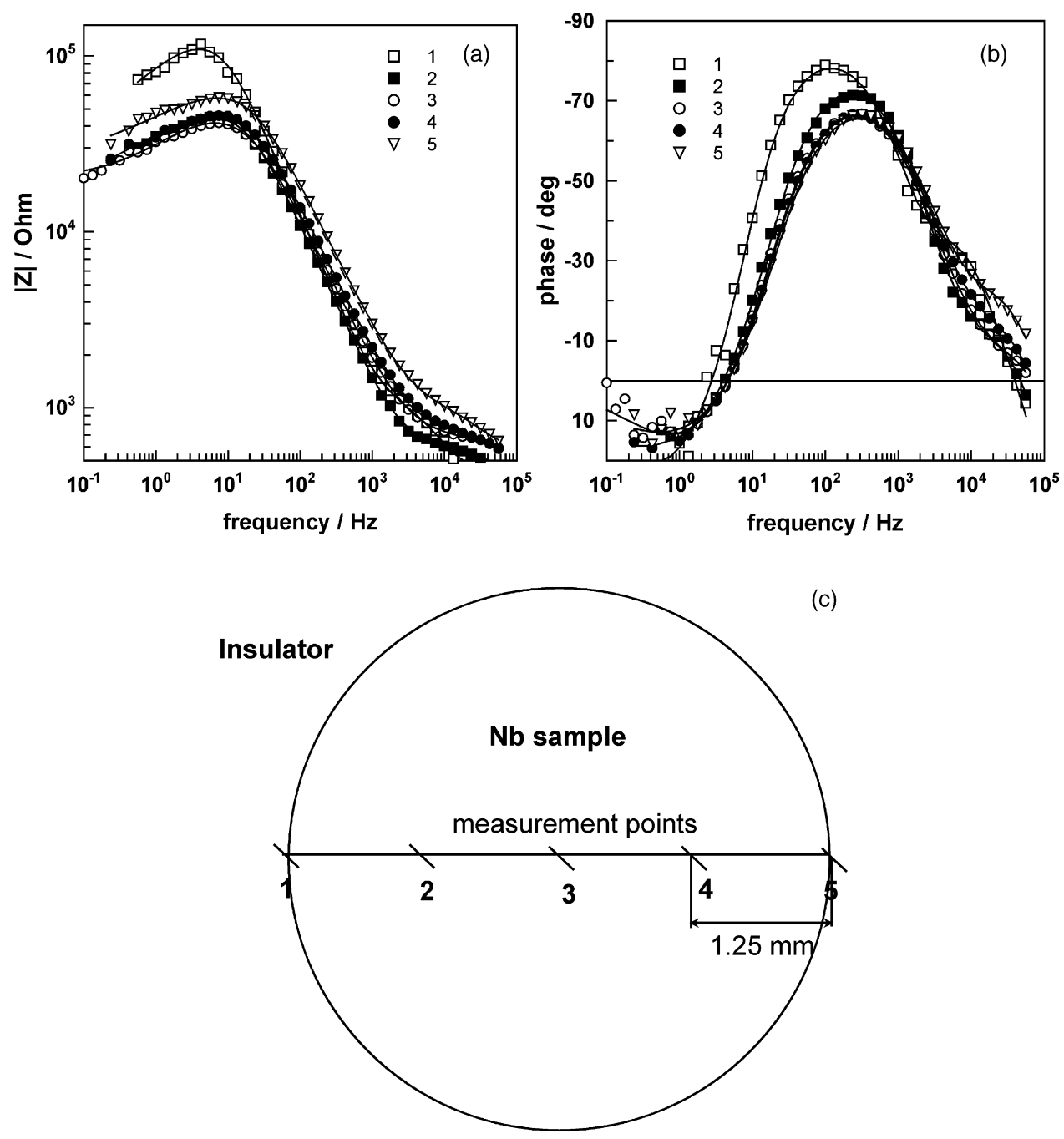

Fig. 5. Local impedance spectra for $\mathrm{Nb}$ oxidised at $5 \mathrm{~V}$ for $1 \mathrm{~h}$ (a: impedance magnitude vs. frequency; b: phase angle vs. frequency) at different points of the electrode surface, as indicated (c). Total diameter of the sample, $5 \mathrm{~mm}$.

ideal behaviour are preserved in the local impedance spectra (see Ref. [10], for comparison).

Using log-log plots of the imaginary part of the impedance versus frequency as suggested in Refs. [10] and [14], an apparent CPE exponent, $\alpha$, has been calculated from both the global and local impedance spectra shown in Figs. 3 and 4. The obtained values are plotted versus potential in Fig. 6. Although the CPE exponent calculated from the local impedance spectra is consistently higher than that calculated from the global spectra, the trend of $\alpha$ with potential is similar for both measurement techniques, which once again indicates a combination between macroscopic 2D and microscopic 3D distributions in analogy to the analysis presented in Ref. [10] for passive Al. The 2D distribution is thought to represent the nanoscopic heterogeneity of the surface of oxidised $\mathrm{Nb}$ representing a combination of crystallised oxide and a nanopore array, as evidenced from the FE-SEM images (Fig. 1).

In order to estimate the high-frequency capacitance and the surface area probed by the local impedance, fits to the highfrequency data of both the global and local impedance from

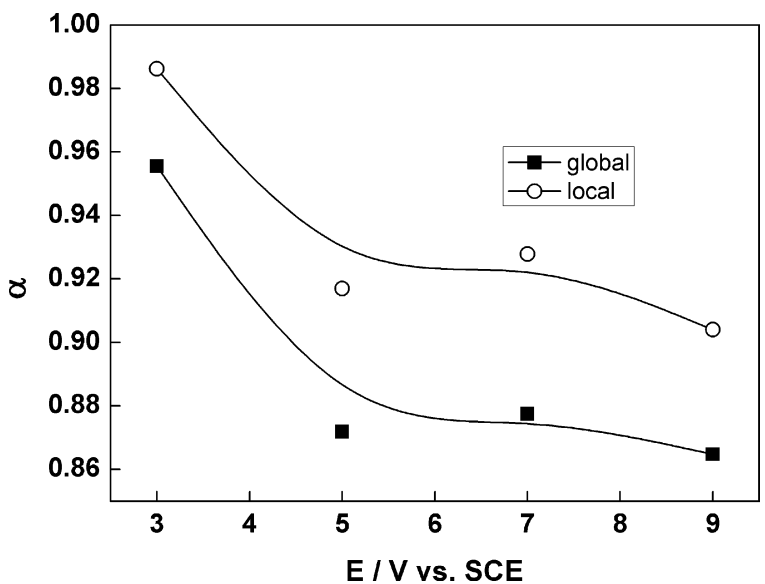

Fig. 6. CPE exponent calculated from the impedance spectra shown in Figs. 3 and 4, respectively. Global values indicated with full symbols and local values with open symbols. 
Figs. 3 and 4 using the Young transfer function $[15,16]$ :

$Z_{\mathrm{Y}}=\frac{p}{j \omega C} \ln \left(\frac{1+j \omega \rho_{\mathrm{d}} \varepsilon \varepsilon_{0} \mathrm{e}^{1 / p}}{1+j \omega \rho_{\mathrm{d}} \varepsilon \varepsilon_{0}}\right)$

where $C$ is the oxide capacitance, $p$ the relative depth of penetration of the defect induced conductivity profile, $\rho_{\mathrm{d}}$ the interfacial resistivity, $\varepsilon$ the dielectric constant of the oxide and $\varepsilon_{0}$ is the permittivity of free space, in a parallel combination with a migration resistance, $R$, have been carried out. The physical meaning of such a combination of parameters is explained in some detail below.

In the formal sense, the Young impedance presumes an exponential decay of the defect induced conductivity of an insulating layer from the interface at which the defects are injected $[15,16]$ and is thus suitable to reproduce a $3 \mathrm{D}$ distribution in the niobium oxide film. Moreover, a completely analogous function that accounts for the electronic properties of the oxide has been recently derived by one of us on the basis of the Mixed-Conduction Model for oxide films [17] starting from a steady-state profile of the major ionic point defect (the oxygen vacancy) acting as an electron donor. Assuming that the mobility of electrons does not change with potential and distance within the film, the electronic conductivity can be expressed as:

$\sigma_{\mathrm{e}}(x)=\frac{F^{2} D_{\mathrm{e}}}{R T} c_{\mathrm{O}}(x)=\frac{F^{2} D_{\mathrm{e}}}{R T} k_{\mathrm{g}}\left[k_{\mathrm{c}}^{-1} \mathrm{e}^{-x / a}+\frac{a}{D_{\mathrm{O}}^{\prime}}\left(1-\mathrm{e}^{-x / a}\right)\right]$

where $c_{\mathrm{O}}(x)$ is the steady-state profile of oxygen vacancies, $D_{\mathrm{e}}$ the diffusion coefficient of electrons, $k_{\mathrm{g}}$ the rate constant of generation of oxygen vacancies at the metal/film interface, $k_{\mathrm{c}}$ the corresponding rate constant of consumption of the same defects at the outer interface, $a$ the half-jump distance and $D_{\mathrm{O}}^{\prime}=D_{\mathrm{O}} \exp (2 F a E / R T)$ is the apparent (field dependent) diffusion coefficient of oxygen vacancies, $E$ being the field strength in the oxide [17]. Using the notation $\rho_{\mathrm{d}}=R T k_{\mathrm{c}} / F^{2} D_{\mathrm{e}} k_{\mathrm{g}}$ and $\rho_{0}=R T D_{\mathrm{O}}^{\prime} / a F^{2} D_{\mathrm{e}} k_{\mathrm{g}}$ to group the parameters depending only on potential but not on the distance within the film, we arrive at:

$\sigma_{\mathrm{e}}(x)=\rho_{\mathrm{d}}^{-1} \mathrm{e}^{-x / a}+\rho_{0}^{-1}$

In order to obtain an expression for the impedance that accounts for the electronic properties of the oxide, we have to integrate that expression over the dimensionless distance $x / L$, where $L$ is the steady state film thickness:

$Z_{\mathrm{e}}=L \int_{0}^{1} \frac{\mathrm{d}(x / L)}{\rho_{\mathrm{d}}^{-1} \exp [-x / p L]+j \omega \varepsilon \varepsilon_{0}+\rho_{0}^{-1}}$

where $p=a / L$. After integration the equation becomes:

$Z_{\mathrm{e}}=\frac{p}{j \omega C+\left(\rho_{0} L\right)^{-1}} \ln \frac{1+\left(j \omega \tau+\rho_{\mathrm{d}} / \rho_{0}\right) \exp (1 / p)}{1+\rho_{\mathrm{d}} / \rho_{0}+j \omega \tau}$

where $\mathrm{C}$ is the film capacitance. Subject to the reasonable assumptions $\rho_{\mathrm{d}} / \rho_{0} \ll 1$ and $\left(\rho_{0} L\right)^{-1} \ll \omega C$, Eq. (5) becomes completely equivalent to Eq. (1). On the other hand, to obtain the impedance due to ionic transport through the oxide, the high-field transport equation for oxygen vacancies:

$J_{\mathrm{O}}(x, t)=-D_{\mathrm{O}} \frac{\partial c_{\mathrm{O}}(x, t)}{\partial x}-\frac{D_{\mathrm{O}}}{2 a} c_{\mathrm{O}}(x, t) \exp \left[\frac{2 F a E(x, t)}{R T}\right]$

has to be solved with the corresponding boundary conditions equalling the transport and reaction fluxes at the interfaces [17]. The solution has the form:

$Z_{\mathrm{ion}}^{-1}=\frac{2 F^{2} D_{\mathrm{O}}^{\prime} c_{\mathrm{O}}(0)\left(1-\alpha_{\mathrm{F} \mid \mathrm{S}}\right)}{R T}\left(\frac{3}{a}+\left(a^{-2}+\frac{4 j \omega}{D_{\mathrm{O}}^{\prime}}\right)^{0.5}\right)$

where $\alpha_{\mathrm{F} \mid \mathrm{S}}$ is the polarisability of the film/solution interface. If the apparent diffusion coefficient $D_{\mathrm{O}}^{\prime}$ is very large (i.e. if the field strength in the film is very high, as usual for oxides on valve metals such as $\mathrm{Nb}$ ), the impedance due to the transport of ionic defects reduces to a resistance, $R$ :

$R^{-1}=\frac{8 F^{2}\left(D_{\mathrm{O}}^{\prime} / a\right) c_{\mathrm{O}}(0)\left(1-\alpha_{\mathrm{F} \mid \mathrm{S}}\right)}{R T}$

The capacitance $C$ and resistance $R$ calculated from such a fitting procedure are plotted in Fig. 7. In accordance to previous calculations based on global impedance data [11], both the inverse of the capacitance and the migration resistance increase in a linear fashion with potential which illustrates the corresponding increase of the barrier layer thickness. The ratio between the capacitance values from the local and global impedance data gives an estimate of ca. $0.09 \mathrm{~cm}^{2}$ for the area probed by the local impedance. At this point, it is worth mentioning that the thickness of the barrier layer estimated from
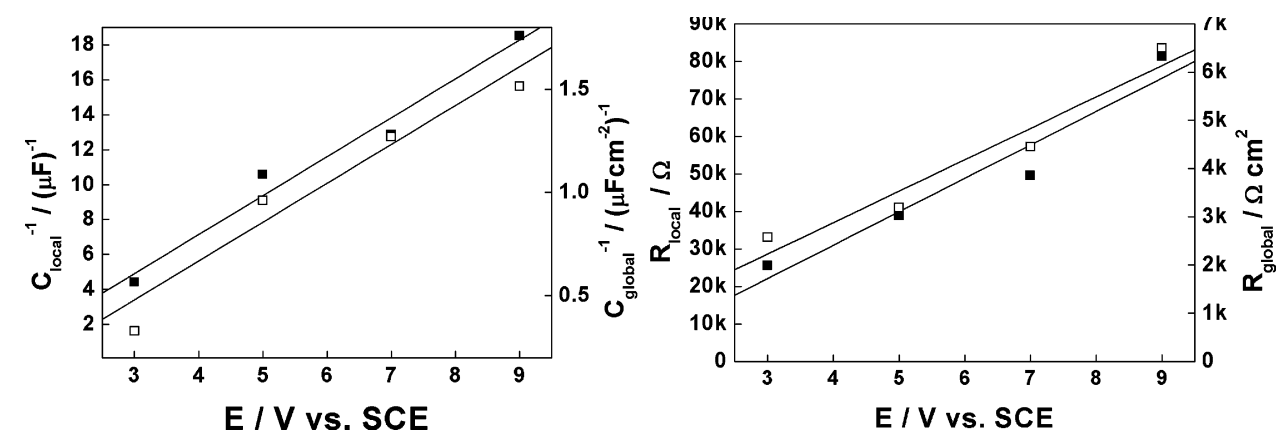

Fig. 7. High-frequency capacitance (left) and parallel resistance (right) as depending on potential calculated from the impedance spectra shown in Figs. 3 and 4. 

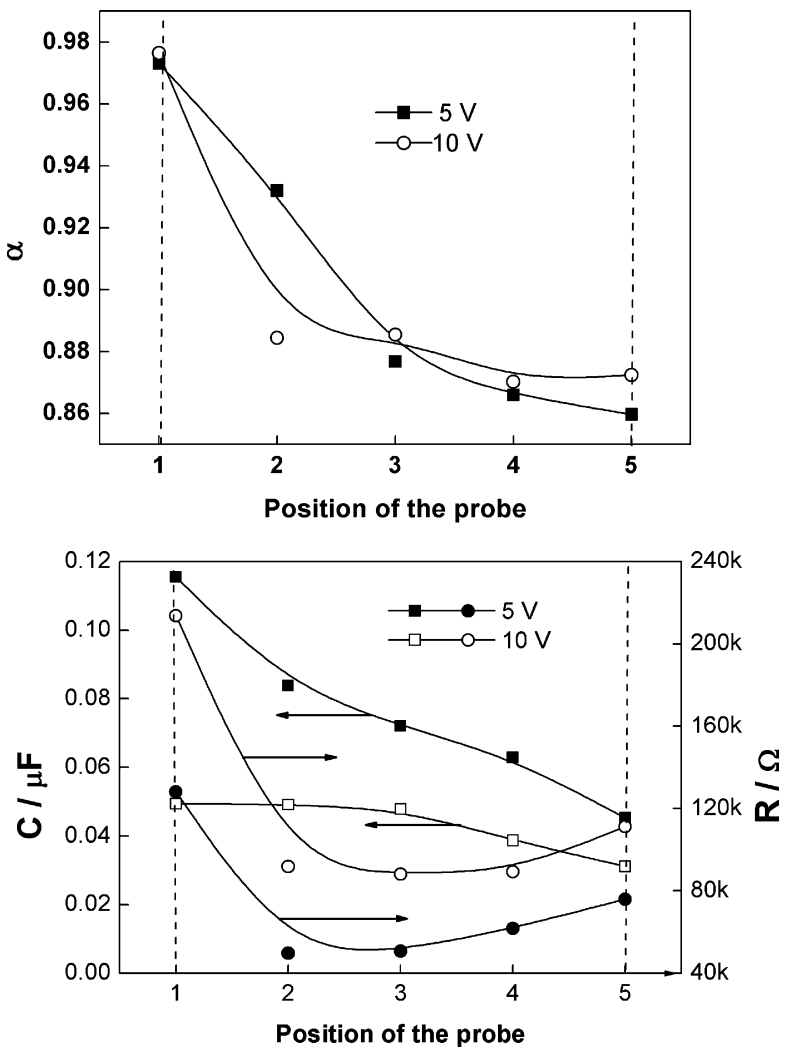

Fig. 8. CPE exponent of the high-frequency time constant (above), capacitance (left ordinate) and resistance (right ordinate) calculated from the local impedance spectra shown in Fig. 5 (below). Dashed lines indicate the boundaries of the $\mathrm{Nb}$ sample.

the capacitance at $10 \mathrm{~V}(30 \mathrm{~nm})$ is in good agreement with that obtained from preliminary transmission electron microscopic (TEM) investigations of the oxide/metal interface.

Similar calculations have been performed for the local impedance data as depending on position (Fig. 5). The calculated values for the apparent CPE exponent, the high-frequency capacitance and migration resistance are collected in Fig. 8 for oxidation potentials of 5 and $10 \mathrm{~V}$. Notwithstanding the lower lateral resolution, the obtained data are to a certain extent similar to those previously reported for passive $\mathrm{Al}$ (a decrease in capacitance and increase of resistance when moving from the centre to the periphery of the electrode [10]). The fact that the decrease in capacitance when moving from the centre to the periphery of the electrode is not symmetrical about the centre is probably also due to the lower resolution obtained in our measurements when compared to those reported in Ref. [10]. Effectively, the resistances and capacitances obtained in points 1 and 5 (Fig. 8) are probably determined with greater uncertainty because the probe senses also a part of the insulator, i.e. a smaller active area is measured at the edge of the electrode.

Another proof for the validity of the conclusions reached on the type of distribution reflected by the deviation of the highfrequency time constant from ideal capacitive behaviour was sought out by measuring ex situ local impedance spectra of films formed in $1 \mathrm{M} \mathrm{H}_{2} \mathrm{SO}_{4}+0.2 \% \mathrm{HF}$ in a plain $0.001 \mathrm{M} \mathrm{Na}_{2} \mathrm{SO}_{4}$. Due to the absence of fluoride ions in the latter electrolyte, it was expected that the rates of the processes of barrier film growth and niobium dissolution will be greatly reduced. As a result, the 3D distribution of conductivity in the oxide is ought to disappear $(\alpha=1)$. Fig. 9 shows the global impedance spectrum of a film formed on $\mathrm{Nb}$ in $1 \mathrm{M} \mathrm{H}_{2} \mathrm{SO}_{4}+0.2 \% \mathrm{HF}$ at $5 \mathrm{~V}$ for $1 \mathrm{~h}$ measured ex situ at the same potential in $0.001 \mathrm{M} \mathrm{Na}_{2} \mathrm{SO}_{4}$, a single time constant with an apparent CPE behaviour being evident. Fig. 10 shows the corresponding local impedance spectra at different surface locations. Once again, single capacitive time constant is observed, but fits to these spectra with a simple parallel $R-C$ combination, as shown in Fig. 10 with solid lines, describe adequately the measured data. This fact indicates that there is no visible 3D distribution, i.e. $\alpha=1$. The calculated values of $R$ and $C$ as depending on the measurement location are collected in Fig. 11. In analogy to the results reported previously for AZ91 Mg alloy [10], the film resistance increases from the centre to the periphery of the electrode, whereas at variance to those results, the capacitance decreases in the same direction. It can be concluded that in the absence of ionic conduction processes only a 2D distribution is observed, which confirms the above hypothesis that the $3 \mathrm{D}$ distribution observed in the
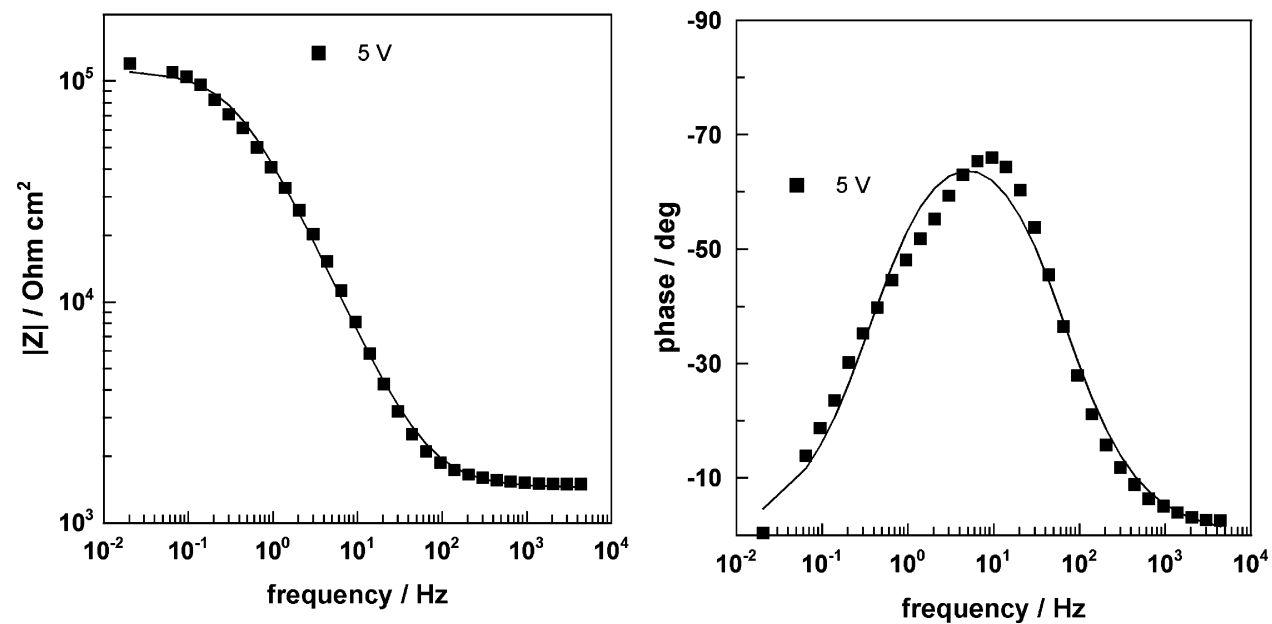

Fig. 9. Global impedance spectrum of a film formed in $1 \mathrm{M} \mathrm{H}_{2} \mathrm{SO}_{4}+0.2 \% \mathrm{HF}$ for $1 \mathrm{~h}$ at $5 \mathrm{~V}$ and measured at the same potential in a $0.001 \mathrm{M} \mathrm{Na}_{2} \mathrm{SO}_{4}$ solution. 

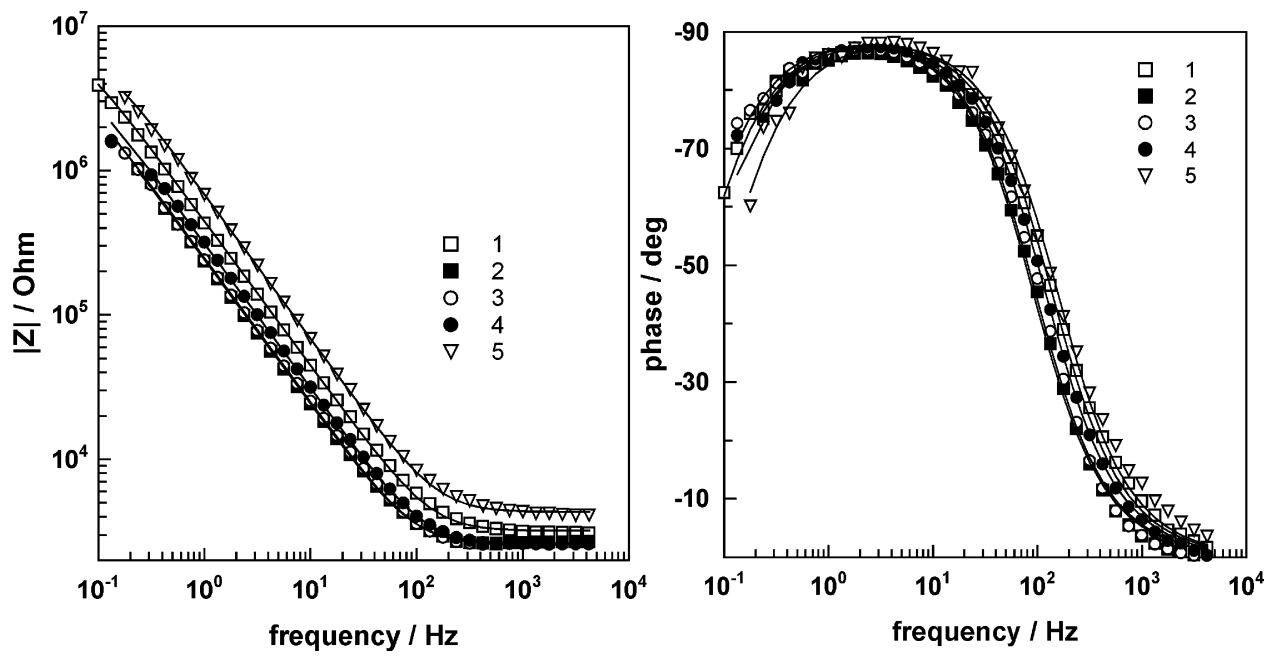

Fig. 10. Local impedance spectra of a film formed in $1 \mathrm{M} \mathrm{H}_{2} \mathrm{SO}_{4}+0.2 \% \mathrm{HF}$ for $1 \mathrm{~h}$ at $5 \mathrm{~V}$ and measured at the same potential in a $0.001 \mathrm{M} \mathrm{Na}_{2} \mathrm{SO}_{4}$ solution at different positions of the LEIS probe, as indicated in Fig. 5.

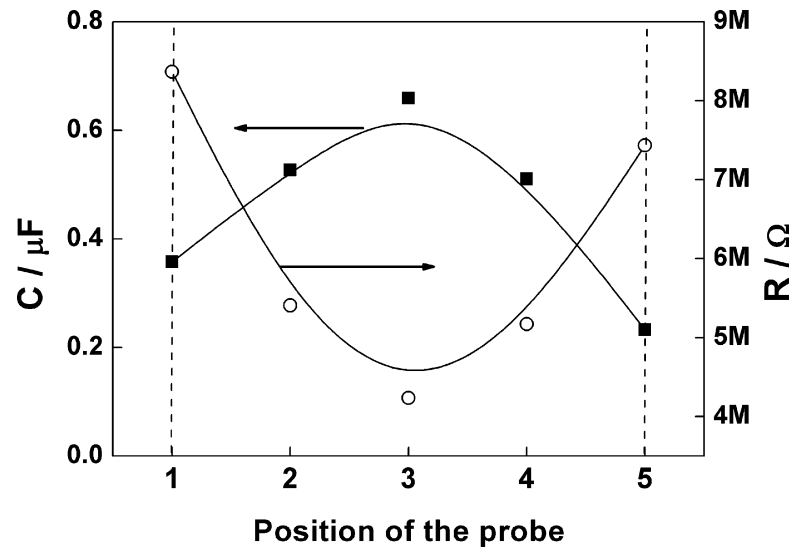

Fig. 11. Dependence of the capacitance and parallel resistance calculated from the spectra shown in Fig. 10 on the position of the LEIS probe.

fluoride-containing solution is due to the faradaic process of film growth and dissolution.

\section{Conclusions}

According to the experimental results and calculations reported in the present paper, the CPE-like distribution of the high-frequency capacitive time constant observed in the impedance spectra of anodically oxidised $\mathrm{Nb}$ in sulphate + fluoride electrolytes is most probably due to:

- a 2D distribution (owed to the fact that both an ordered crystallisation structure and an array of nanopores are present at the oxide/electrolyte interface, resulting in a lateral variation of both the oxide resistance and capacitance);

- a 3D distribution, resulting from the profiles of defect induced conductivity in the bulk oxide owed to the processes of barrier layer growth, $\mathrm{Nb}$ dissolution through the barrier layer/subsequent formation of a porous overlayer. As a first approximation, this 3D distribution was modelled using the Mixed-Conduction Model for oxide films within the frames of which a transfer function formally analogous to the Young impedance which incorporates an exponential decay of conductivity away from the interface at which the point defects inducing it are produced has been derived.

In a more sophisticated model of the system, also the distribution of the low-frequency inductive time constant probably resulting from surface and volume variation of the rate of interaction between main point defects and oppositely charged minority defects, has to be quantitatively taken into account. Due to the complexity of the phenomena involved, this issue is expected to be resolved by numerical calculations of the transport processes in the barrier layer and the nanopores. Such calculations are underway and will be reported in the near future.

\section{Acknowledgements}

The authors are indebted to Jean-Baptiste Jorcin (CIRIMAT, ENSIACET) for his valuable help with the local impedance spectroscopy technique, and to Djar Oquab (CIRIMAT, ENSIACET) for the FE-SEM observations. The financial support of the ERASMUS programme for BT is also gratefully acknowledged.

\section{References}

[1] H. Tsuchiya, P. Schmuki, Electrochem. Commun. 6 (2004) 1131.

[2] I. Sieber, H. Hildebrand, A. Friedrich, P. Schmuki, Electrochem. Commun. 7 (2005) 97.

[3] J. Choi, J.H. Lim, S.C. Lee, J.H. Chang, K.J. Kim, M.A. Cho, Electrochim. Acta 51 (2006) 5502

[4] M. Ohtaki, J. Peng, K. Eguchi, H. Arai, Sens. Actuators B13/14 (1993) 495.

[5] G.H. Hutching, S.H. Taylor, Catal. Today 49 (1999) 105.

[6] R.I. Aagard, Appl. Phys. Lett. 27 (1975) 605.

[7] B. Ohtani, K. Iwai, S. Nishimoto, T. Inui, J. Electrochem. Soc. 141 (1994) 2439.

[8] M. Bojinov, S. Cattarin, M. Musiani, B. Tribollet, Electrochim. Acta 48 (2003) 4107 
[9] G. Baril, C. Blanc, M. Keddam, N. Pébère, J. Electrochem. Soc. 150 (2003) B493.

[10] J.-B. Jorcin, M.E. Orazem, N. Pébère, B. Tribollet, Electrochim. Acta 51 (2006) 1473

[11] S. Cattarin, M. Musiani, B. Tribollet, J. Electrochem. Soc. 149 (2002) B457.

[12] H. Habazaki, T. Ogasawara, H. Konno, K. Shimizu, K. Asami, S. Nagata, P. Skeldon, G.E. Thompson, in: P. Marcus, V. Maurice (Eds.), Passivation of Metals and Semiconductors, and Properties of Thin Oxide Layers, Elsevier, 2006, p. 211.
[13] M. Bojinov, Electrochim. Acta 42 (1997) 3489.

[14] M.E. Orazem, N. Pébère, B. Tribollet, J. Electrochem. Soc. 153 (2006) B129.

[15] L. Young, Trans. Faraday Soc. 51 (1955) 1250.

[16] H. Göhr, J. Schaller, C.-A. Schiller, Electrochim. Acta 38 (1993) 1961.

[17] M. Bojinov, G. Fabricius, P. Kinnunen, T. Laitinen, K. Mäkelä, T. Saario, G. Sundholm, J. Electroanal. Chem. 504 (2001) 29. 